\title{
BMJ
}

\section{Improved effectiveness of partner notification for patients with sexually transmitted infections: systematic review}

\author{
Sven Trelle, research fellow ${ }^{1}$, Aijing Shang, research fellow' ${ }^{1}$ Linda Nartey, specialist registrar ${ }^{1}$, Jackie A \\ Cassell, honorary senior clinical research fellow ${ }^{2}$, Nicola Low, reader in epidemiology and public \\ health
}

\begin{abstract}
${ }^{1}$ Department of Social and Preventive Medicine, University of Bern, Finkenhubelweg 11, Bern, $\mathrm{CH}$ 3012, Switzerland

${ }^{2}$ Centre for Sexual Health and HIV Research, Royal Free and University College Hospitals Medical School, London

Correspondence to:

N Low low@ispm.unibe.ch
\end{abstract}

doi: 10.1136/bmi.39079.460741.7C

\section{ABSTRACT}

Objective To examine the effectiveness of methods to improve partner notification by patient referral (index patient has responsibility for informing sex partners of their exposure to a sexually transmitted infection). Design Systematic review of randomised trials of any intervention to supplement simple patient referral. Data sources Seven electronic databases searched (January 1990 to December 2005) without language restriction, and reference lists of retrieved articles. Review methods Selection of trials, data extraction, and quality assessment were done by two independent reviewers. The primary outcome was a reduction of incidence or prevalence of sexually transmitted infections in index patients. If this was not reported data were extracted according to a hierarchy of secondary outcomes: number of partners treated; number of partners tested or testing positive; and number of partners notified, located, or elicited. Random effects meta-analysis was carried out when appropriate. Results 14 trials were included with 12389 women and men diagnosed as having gonorrhoea, chlamydia, nongonococcal urethritis, trichomoniasis, or a sexually transmitted infection syndrome. All studies had methodological weaknesses that could have biased their results. Three strategies were used. Six trials examined patient delivered partner therapy. Metaanalysis of five of these showed a reduced risk of persistent or recurrent infection in patients with chlamydia or gonorrhoea (summary risk ratio $0.73,95 \%$ confidence interval 0.57 to 0.93 ). Supplementing patient referral with information for partners was as effective as patient delivered partner therapy. Neither strategy was effective in women with trichomoniasis. Two trials found that providing index patients with chlamydia with sampling kits for their partners increased the number of partners who got treated. Conclusions Involving index patients in shared responsibility for the management of sexual partners improves outcomes. Health professionals should consider the following strategies for the management of individual patients: patient delivered partner therapy, home sampling for partners, and providing additional information for partners.

\section{INTRODUCTION}

Partner notification is an important part of managing sexually transmitted infections. ${ }^{1}$ This includes identifying sex partners, informing them of their exposure, ensuring evaluation or treatment, and providing advice on preventing further infections. ${ }^{2}$ The stigma attached to sexually transmitted infections makes partner notification difficult. ${ }^{3}$ More partners are likely to be treated if a health professional contacts them on behalf of the patient (provider referral) than if patients do this themselves (patient referral). ${ }^{4}$ In practice, however, both patients ${ }^{5}$ and doctors ${ }^{6}$ prefer patient referral, which is cheaper ${ }^{6-8}$ and easier to do in primary care, where increasing numbers of sexually transmitted infections are being diagnosed. ${ }^{9}$ Current methods of patient referral only reach $40-60 \%$ of named sexual partners, ${ }^{10}$ so new strategies are needed.

The National Institute for Health and Clinical Excellence will provide guidance about interventions to reduce the transmission of sexually transmitted infections, including partner notification, in February 2007 (www.nice.org.uk). Because none of the published systematic reviews of partner notification included new methods to improve patient referral $^{41112}$ we systematically reviewed the literature to examine their effectiveness.

\section{METHODS}

We searched seven electronic databases without language restrictions from January 1990 to December 2005 (Medline, Embase, Cinahl, Cochrane Library, PsycINFO, Sigle, DARE) and the reference lists of relevant reports. Subject headings and free text words covering specific sexually transmitted infections were combined with terms for partner notification (detailed search strategy available from the authors). We also searched two electronic research registers (international standard randomised controlled trial number and clinicaltrials.gov) using the search term "partner notification".

We considered all sexually transmitted infections. We included trials that compared simple patient referral with patient referral supplemented by 
methods aimed at improving its effectiveness. We defined simple patient referral as an intervention in which the index patient had responsibility for informing their sexual partners about the infection and advising them to seek treatment. This could be done with or without contact cards, which are given by index patients to partners and contain the diagnosis and address of the clinic.

Two authors independently screened titles and abstracts. If eligibility could not be assessed we obtained a full text version. Disagreements were resolved by discussion. Duplicate reports were identified and data extracted from the most recent publication.

Data on setting, participants, interventions, outcomes, and quality were independently extracted by two authors using a piloted, standardised form. We used published checklists to assess methodological quality. ${ }^{13}$ Disagreements were resolved by discussion.

\section{Outcome measures}

We defined the primary outcome as a reduction of incidence or prevalence of sexually transmitted infections in index patients. This is the most objectively measured outcome and is directly related to the public health aim of controlling the spread of sexually transmitted infections. If the primary outcome was not reported we extracted data according to a hierarchy of secondary, intermediate outcomes: number of partners treated; number of partners tested or testing positive; and number of partners notified, located, or elicited.

\section{Statistical analysis}

For outcomes reported as proportions we calculated exact $95 \%$ confidence intervals or two sided $P$ values. For outcomes reported as mean numbers per index case we did not carry out additional calculations because we could not account for the clustering of the data. When more than two trials examined the same intervention we combined results using random effects meta-analysis. ${ }^{14}$ Statistical evidence of heterogeneity was assessed using Cochran's $Q$ and the $\mathrm{I}^{2}$ statistic, which describes the percentage of total variation across trials that is attributable to heterogeneity rather than chance. ${ }^{15} \mathrm{I}^{2}$ values of $25 \%, 50 \%$, and $75 \%$ correspond to low, moderate, and high heterogeneity between trials. In meta-analyses with at least five trials we examined funnel plots and did a statistical test for small study effects. ${ }^{16}$ We used Stata 9.2 for all analyses.

\section{RESULTS}

Overall, 2493 unique references were identified and 290 full text manuscripts retrieved, including two reports from unpublished studies (fig 1). ${ }^{\text {w13w14 }}$ Fourteen trials examining 16 interventions in 12389 people were included. Included trials studied patients with gonorrhoea, chlamydia, trichomoniasis, non- specific urethritis, or syndromically diagnosed infections (table; a more detailed table of the included studies is available from the authors on www.ispm.ch/ index.php?id=1193). We found no relevant trials on syphilis, HIV, or other infections. We identified three strategies for improving the yield of patient referral. Six trials evaluated interventions in which the index case was given drugs or a prescription for their partners (patient delivered partner therapy). ${ }^{\text {w1-w6 }}$ Two of these also compared patient delivered partner therapy with additional information for index patients to give to partners. ${ }^{\mathrm{w} 1 \mathrm{w} 2}$ Two trials evaluated providing index patients diagnosed as having chlamydia with sampling kits for partners. ${ }^{\text {w w8 }}$ Eight trials evaluated providing additional written, visual, or verbal information. ${ }^{\text {w7w8w9-w14 }}$ Four trials were carried out

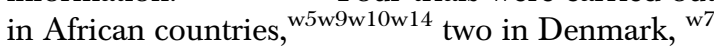
w8 and eight in the United States. ${ }^{\text {w1-w4w6w11-w13 }}$

\section{Methodological quality}

All included studies had methodological weaknesses that could have biased their results (see table of quality assessment on www.ispm.ch/index.php? $\mathrm{id}=1193)$. Only four trial reports described an adequate method of generating a random allocation sequence, ${ }^{\mathrm{w} 1 \mathrm{w} 5 \mathrm{w} 9 \mathrm{w} 10}$ and concealment was adequate in only one of these. ${ }^{\mathrm{w} 9}$ One other trial concealed allocation by using sealed, opaque, sequentially numbered envelopes. ${ }^{\mathrm{w} 4}$ Two trials used systematic allocation sequences (date of birth ${ }^{\mathrm{w} 7}$ and month of presentation $^{w 2}$ ) that could not be concealed. One trial was described as an observational cohort, in which women were randomly assigned to different healthcare providers. ${ }^{\text {w6 }}$ No description was provided of sequence generation or allocation concealment. No other trial described the concealment of allocation. ${ }^{\text {w3w6w8w11-w14 }}$ Six trials measured our predefined primary outcome. ${ }^{\text {w1-w4w6w13 }}$ Five of these also measured at least one secondary outcome. ${ }^{\mathrm{w} 1-\mathrm{w} 4}$ ${ }^{\text {w13 }}$ Of trials measuring only secondary outcomes, three assessed the numbers of partners treated, ${ }^{\text {w5w11 }}$

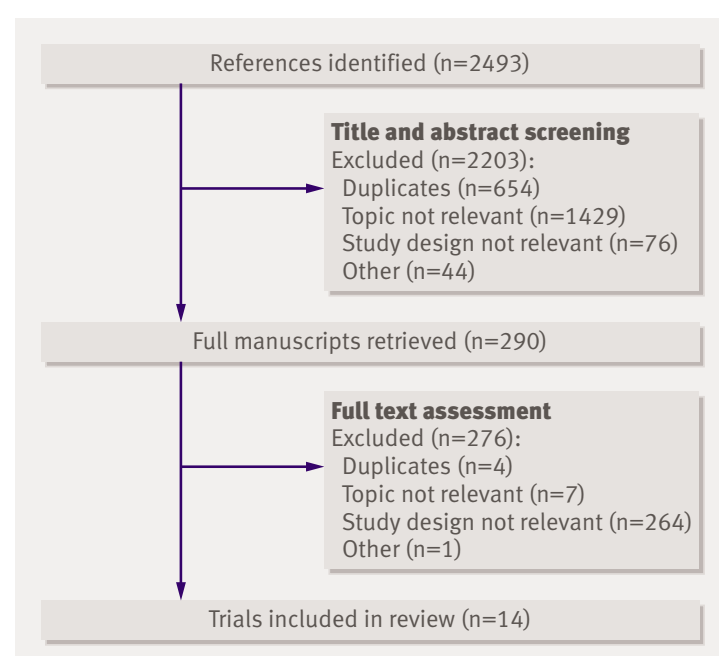

Fig 1| Flowchart of trial selection 


\begin{tabular}{|c|c|c|c|c|}
\hline Study reference & Participants & Interventions & No of patients & Primary outcome and results \\
\hline Kissinger et al $2006^{\mathrm{w} 1}$ & Women with Trichomonas vaginalis & $\begin{array}{l}\text { Intervention 1, patient delivered partner therapy; } \\
\text { intervention 2, patient referral plus information for } \\
\text { partner; control, patient referral }\end{array}$ & 463 & $\begin{array}{l}\text { Persistent or recurrent infections: intervention } 1 \\
9.4 \% \text {; intervention } 29.0 \% \text {; control } 6.3 \% \text {; } P=0.64\end{array}$ \\
\hline Golden et al $2005^{\mathrm{w} 3}$ & $\begin{array}{l}\text { Men and women with Neisseria } \\
\text { gonorrhoeae or Chlamydia } \\
\text { trachomatis }\end{array}$ & $\begin{array}{l}\text { Intervention: patient delivered partner therapy; } \\
\text { control, patient referral }\end{array}$ & 2751 & $\begin{array}{l}\text { Persistent or recurrent infections: intervention } 10 \% \text {; } \\
\text { control } 13 \% ; \mathrm{P}=0.04\end{array}$ \\
\hline Kissinger et al $2005^{\mathrm{w} 2}$ & $\begin{array}{l}\text { Men with } N \text { gonorrhoeae or } C \\
\text { trachomatis }\end{array}$ & $\begin{array}{l}\text { Intervention 1, patient delivered partner therapy; } \\
\text { intervention 2, patient referral plus information for } \\
\text { partner; control, patient referral }\end{array}$ & 977 & $\begin{array}{l}\text { Persistent or recurrent infections: intervention } 1 \\
6 \% \text {; intervention } 25 \% \text {; control 12\%; P< } 0.01\end{array}$ \\
\hline Schillinger et al $2003^{\mathrm{w} 4}$ & Women with C trachomatis & $\begin{array}{l}\text { Intervention: patient delivered partner therapy; } \\
\text { control, patient referral }\end{array}$ & 1889 & $\begin{array}{l}\text { Persistent or recurrent infections: intervention } 12 \% \text {; } \\
\text { control } 15 \% ; \mathrm{P}=0.11\end{array}$ \\
\hline Ostergaard et al $2003^{\mathrm{w} 8}$ & Men and women with $C$ trachomatis & $\begin{array}{l}\text { Intervention: patient referral plus home sampling; } \\
\text { control: patient referral plus sampling kit to take to } \\
\text { healthcare provider }\end{array}$ & $\begin{array}{l}1826(562 \\
\text { enrolled) }\end{array}$ & $\begin{array}{l}\text { Partners tested per index patient: men-intervention } \\
0.16 \text {, control } 0.04 ; P<0.0001 \text {; women-intervention } \\
0.31 \text {; control } 0.14 ; p<0.0001\end{array}$ \\
\hline Moyo et al $2002^{\text {w9 }}$ & $\begin{array}{l}\text { Men and women with syndromic } \\
\text { bacterial sexually transmitted } \\
\text { infections }\end{array}$ & $\begin{array}{l}\text { Intervention: patient referral plus interactive } \\
\text { questions and answers* plus voucher for health } \\
\text { care; control: patient referral (unclear, } 30 \text { minute } \\
\text { interview) }\end{array}$ & 272 & $\begin{array}{l}\text { Proportion with } \geq 1 \text { partner notified: intervention } \\
92 \% \text {; control } 67 \% \text {; } P<0.001\end{array}$ \\
\hline Nuwaha et al $2001^{\text {w5 }}$ & $\begin{array}{l}\text { Men and women with syndromic } \\
\text { sexually transmitted infections }\end{array}$ & $\begin{array}{l}\text { Intervention: patient delivered partner therapy; } \\
\text { control: patient referral }\end{array}$ & 383 & $\begin{array}{l}\text { Partners treated or referred per partner elicited: } \\
\text { intervention } 74 \% \text {; control } 34 \% \text {; risk ratio } 2.44 \text { ( } 95 \% \\
\text { confidence interval } 1.95 \text { to } 3.07 \text { ) }\end{array}$ \\
\hline Kissinger et al $1998^{\text {w6 }}$ & Women with C trachomatis & $\begin{array}{l}\text { Intervention: patient delivered partner therapy; } \\
\text { control: patient referral }\end{array}$ & 256 & $\begin{array}{l}\text { Persistent or recurrent infections: intervention } 12 \% \text {; } \\
\text { control } 22 \% ; \mathrm{P}<0.05\end{array}$ \\
\hline Andersen et al $1998^{\mathrm{w} 7}$ & Women with C trachomatis & $\begin{array}{l}\text { Intervention: patient referral plus home sampling; } \\
\text { control: patient referral plus sampling kit to take to } \\
\text { healthcare provider }\end{array}$ & 96 & $\begin{array}{l}\text { Partners tested positive per index patient: } \\
\text { intervention } 0.27 \text {; control } 0.14 \text {; difference } 0.13 \\
(95 \% \text { confidence interval }-0.03 \text { to } 0.29 \text { ) }\end{array}$ \\
\hline Faxelid et al $1996^{\mathrm{w} 10}$ & $\begin{array}{l}\text { Men and women with sexually } \\
\text { transmitted disease }\end{array}$ & $\begin{array}{l}\text { Intervention: patient referral plus interactive } \\
\text { questions and answers* plus educationt; control: } \\
\text { usual care (no other details) }\end{array}$ & 396 & $\begin{array}{l}\text { Proportion with } \geq 1 \text { partner notified: men: } \\
\text { intervention } 100 \% \text {; control } 93 \% \text {; } \mathrm{P}=0.001 \text {; women: } \\
\text { intervention } 72 \% \text {; control } 56 \% ; \mathrm{P}=0.14\end{array}$ \\
\hline Katz et al $1988^{\text {w11 }}$ & Men with non-gonococcal urethritis & $\begin{array}{l}\text { Intervention: patient referral plus interactive } \\
\text { questions and answers* plus educationt; control: } \\
\text { patient referral }\end{array}$ & 457 & $\begin{array}{l}\text { Partners treated per index patient: intervention } \\
0.22 \text {; control } 0.18 \text {; difference } 0.04 \text { ( } 95 \% \text { confidence } \\
\text { interval }-0.04 \text { to } 0.12 \text { ) }\end{array}$ \\
\hline $\begin{array}{l}\text { Solomon and Dejong } \\
1988^{\text {w12 }}\end{array}$ & Men with $N$ gonorrhoeae & $\begin{array}{l}\text { Intervention: patient referral plus educationt; } \\
\text { control: patient referral }\end{array}$ & 902 & Partners tested: "no significant difference" \\
\hline Cleveland $2001^{\text {w13 }}$ & Men and women with $\mathrm{Ngonorrhoeae}$ & $\begin{array}{l}\text { Intervention: patient referral plus interactive } \\
\text { questions and answers* plus educationt; control: } \\
\text { patient referral }\end{array}$ & 1266 & $\begin{array}{l}\text { Persistent or recurrent infections: intervention } 6 \% \text {; } \\
\text { control } 8 \% ; P=0.76\end{array}$ \\
\hline Ellison et al $2001^{\text {w14 }}$ & $\begin{array}{l}\text { Sex unclear; syndromic sexually } \\
\text { transmitted infections }\end{array}$ & $\begin{array}{l}\text { Intervention 1: patient referral plus educationt; } \\
\text { intervention 2: patient referral plus interactive } \\
\text { questions and answers; intervention } 3: \text { patient } \\
\text { referral plus interactive questions* and answers } \\
\text { plus educationt; control: patient referral }\end{array}$ & 1719 & $\begin{array}{l}\text { Partners treated per index patient: intervention } 1 \\
0.20 \text {; intervention } 20.22 \text {; intervention } 30.25 \text {; } \\
\text { control } 0.18\end{array}$ \\
\hline
\end{tabular}

Results are presented according to primary analysis presented in report (P values or confidence intervals calculated if not reported and enough details reported). Differences do not necessarily add up owing to rounding. For additional details see table provided by authors on www.ispm.ch/index.php?id=1193.

*Interactive questions and answers include all interventions described as counselling or discussions with patients.

${ }^{\text {w14 }}$ three measured numbers of partners tested, ${ }^{\mathrm{w} 7 \mathrm{w} 8}$ w12 and two measured numbers of partners notified. ${ }^{\text {w9w10 }}$ Assessment of outcomes was potentially biased in all but one study that used blinded ascertainment. ${ }^{\text {w14 }}$ In addition, patients in the intervention but not the control group were refunded their transport fare, and outcomes in the two groups were assessed differently in one trial. ${ }^{\text {w5 }}$ In another two trials examining patient delivered partner therapy, the wording of the question assessing the outcome would have underestimated the proportion of partners treated in the control groups. ${ }^{\text {ww2 } 2}$ In six trials, ${ }^{\text {w1-w5w9 }}$ in addition to the intervention itself participants in the experimental group received materials or benefits that could have contributed to the observed effect.

\section{Patient delivered partner therapy}

Over 6000 patients (4912 women, 1807 men) were enrolled in six trials of patient delivered partner therapy. ${ }^{\text {w1-w6 }}$ In one trial from Uganda, ${ }^{\text {w5 }}$ and one from the United States, ${ }^{\text {w6 }}$ index patients in the intervention group received packets containing only the drugs. In the other trials packets also contained information on the drugs and details of how to contact health professionals. ${ }^{\text {w1-w4 }}$ One trial also included information about the infection, ${ }^{\mathrm{w} 4}$ and one included condoms with the other materials. ${ }^{\text {w3 }}$ The control groups received simple patient referral without contact cards in three trials ${ }^{\text {w1-w3 }}$ and with contact cards in three trials. $^{\text {w4-w6 }}$

The rate of persistent or recurrent infections in patients managed with patient delivered partner therapy was lower than in controls among index cases with chlamydia or gonorrhoea but not with trichomonas. In five trials providing sufficient data the summary risk ratio compared with simple patient referral was 0.73 (95\% confidence interval 0.57 to 0.93$)$, with some evidence of statistical heterogeneity $\left(\mathrm{I}^{2} 37 \%\right.$, $\mathrm{P}=0.18$; fig 2). ${ }^{\mathrm{w} 1-\mathrm{w} 4 \mathrm{w} 6}$ If $10 \%$ of patients managed 
with simple patient referral had persistent or recurrent infections, the absolute risk reduction would be $3.7 \%(0.7 \%$ to $4.3 \%)$ and the number needed to treat would be 27 (23 to 143). No statistical evidence was found for small study effects $(\mathrm{P}=0.91)$. Four trials provided enough details for meta-analysis of the proportion of partners treated per partner elicited. ${ }^{\text {w1-w3w5 }}$ All four trials favoured patient delivered partner therapy, and the meta-analysis showed a relevant increase in the number of partners treated (risk ratio 1.44, 95\% confidence interval 1.12 to 1.86$)$, but statistical heterogeneity was high $\left(\mathrm{I}^{2} 94 \%, \mathrm{P}<0.0001\right.$; fig 2$)$. The relatively large size of trials results in small standard errors, which can inflate the $\mathrm{I}^{2}$ statistic.

Two trials compared patient delivered therapy with patient referral supplemented by booklets with tearout cards and treatment guidelines for index patients to give to partners. ${ }^{\text {w1w2 }}$ The proportions of index patients with persistent or recurrent infection with chlamydia, gonorrhoea, or trichomonas were similar in the two groups in both trials but data were insufficient for meta-analysis (see table of included studies on www.ispm.ch/index.php?id=1193). The proportion of partners treated was higher in patients receiving patient delivered partner therapy (summary risk ratio $1.25,95 \%$ confidence interval 1.15 to $1.37 ; \mathrm{I}^{2}$ $0 \%, \mathrm{P}=0.44$; fig 3 ).

Persistent or recurrent infections

$\begin{array}{lc}\text { Study } & \begin{array}{c}\text { No of } \\ \text { patients }\end{array} \\ \text { Kissinger et al } 1998^{\mathrm{w} 6} & 256 \\ \text { Schillinger et al } 2003^{\mathrm{w} 4} & 1889 \\ \text { Golden et al } 2005^{\mathrm{w} 3} & 2751 \\ \text { Kissinger et al } 2005^{\mathrm{w} 2} & 629 \\ \text { Kissinger et al } 2006^{\mathrm{w} 1} & 309 \\ \text { Overall }\left(I^{2}=37 \%, \mathrm{P}=0.18\right) & \end{array}$
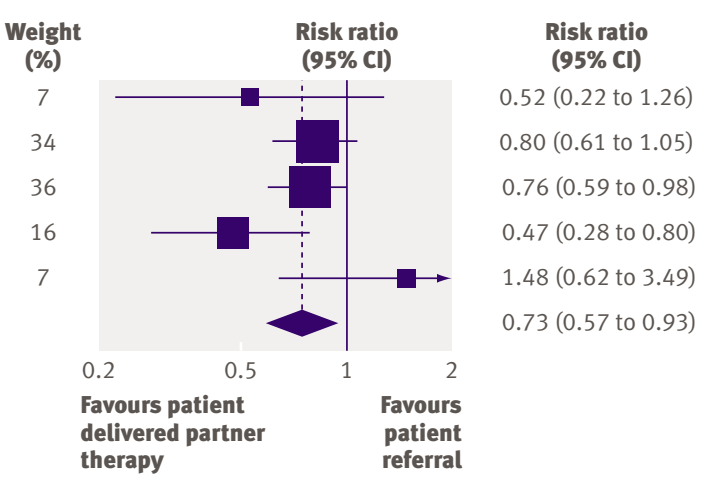

Partners treated per elicited partner

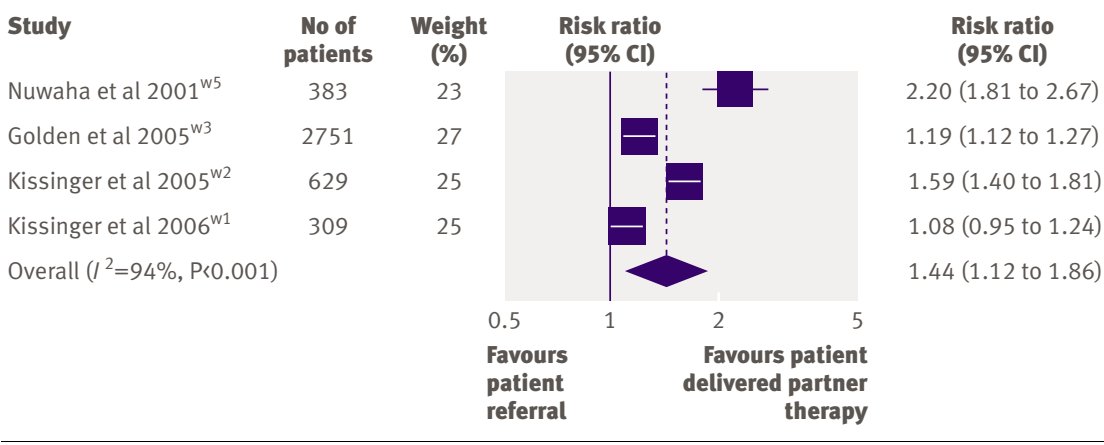

Fig 2 Random effects meta-analyses of primary and secondary outcomes of trials comparing patient delivered partner therapy with simple patient referral. All trials except for Schillinger et al $2003^{\mathrm{w} 4}$ had unclear or inadequate concealment of allocation

\section{Home sampling}

Both trials on home sampling were carried out among patients with chlamydia in Denmark. ${ }^{\mathrm{w} 7 \mathrm{w} 8}$ The earlier trial included 96 women. ${ }^{\text {w7 }}$ In the larger trial, 1826 patients were randomised but only 562 (414 women and 148 men) consented. $^{\text {w8 }}$ Index patients in the intervention groups received sterile containers, information on how to collect specimens, and a prepaid envelope. They were advised to give the kits to sex partners, who could collect specimens at home and mail them to the laboratory. Patients in the control group were instructed to tell their partners to take the sampling kit to their doctor. In both trials home sampling increased the number of partners tested and the number of identified infected partners (table). On the basis of the results of the larger trial ${ }^{\mathrm{w} 8} 8$ (95\% confidence interval, 7 to 11) index patients would need sampling kits to have one additional index patient with at least one partner tested.

\section{Providing additional information}

Eight trials enrolled a total of 6452 patients. ${ }^{\text {w1w2w9-w14 }}$ Two trials in the United States (1440 patients) compared the provision of additional information for index cases to give to their partners with simple patient referral (table). ${ }^{\text {w1w2 }}$ One enrolled men with gonorrhoea or chlamydia ${ }^{\text {w2 }}$ and the other studied women with trichomoniasis. ${ }^{\text {w1 }}$ The other six trials evaluated different forms of information for the index patient only. Of these, three (2387 patients) in resource poor countries studied women and men with a variety of laboratory or syndromically diagnosed infections. ${ }^{\text {w9w10w14 }}$ Three studies in the United States enrolled 2625 men with gonorrhoea or non-gonococcal urethritis. ${ }^{\text {w11-w13 }}$ Four trials used simple patient referral without a contact card, ${ }^{\text {w1w2w10w11 }}{ }^{w}$ three used patient referral with contact cards, ${ }^{\text {w12-w14 }}$ and in two trials the control intervention was not standardised $^{\mathrm{w} 10}$ or was unclear. ${ }^{\mathrm{w} 9}$ Outcome assessments included follow-up interviews with index patients ${ }^{\mathrm{w} 1 \mathrm{w} 2 \mathrm{w} 9 \mathrm{w} 10}$ and counting of partners attending the trial centre but not other clinics. ${ }^{\text {w11-w14 }}$

The types of additional information were categorised as written information to be given to partners $^{\mathrm{w} 1 \mathrm{w} 2}$; information for index cases provided through counselling or discussion (interactive question and answer sessions) ${ }^{\text {w9w14}}$; structured verbal education for index patients, such as being read a script or being asked to watch a videow12w14; and combinations of information types. ${ }^{\text {w10-w13 }}$

\section{Written information for partners}

In one trial 348 men with gonorrhoea or chlamydia received booklets with tear-out cards providing information for partners and treatment guidelines for health professionals in addition to simple patient referral, and 285 controls received simple patient referral. ${ }^{\text {w2 }}$ The proportion of persistent or recurrent infections among index patients with chlamydia or gonorrhoea who received additional information 
was lower than in controls $(5 \%$ v $12 \%$; $\mathrm{P}<0.01$; risk ratio $0.37,95 \%$ confidence interval 0.21 to 0.66 ), and partners were treated more often in the group who received additional information for partners $(46 \% v$ $35 \%$ of partners; $\mathrm{P}<0.01$; risk ratio $1.30,1.13$ to 1.49). The other trial examined the same interventions in women with trichomonas: 154 received additional information for their partners and 155 received simple patient referral. ${ }^{\mathrm{w} 1}$ Rates of persistent or recurrent infection in index patients were similar $(9 \% v 6 \%$; $\mathrm{P}=0.64$; risk ratio $1.42,0.59$ to 3.41 ). Fewer index patients in the group receiving the booklet than in the control group reported that their partners had taken the treatment $(58 \% v 70 \% ; \mathrm{P}<0.01$; risk ratio $0.82,0.69$ to 0.98 ). No meta-analysis was carried out on the results of these two trials.

\section{Interactive question and answer session for index cases}

One trial in South Africa found no additional benefit in numbers of partners treated compared with patient referral with contact cards. ${ }^{\text {w14 }}$ One trial in Zimbabwe supplemented an interactive question and answer session with a healthcare voucher for partners and found statistical evidence of benefit in the number of index patients with at least one partner notified $(92 \% v 67 \%$; $\mathrm{P}<0.001){ }^{\text {w9 }}$

\section{Structured verbal education or video}

Two trials that evaluated information given from a structured script or asked patients to watch a video found no effect on partners tested or treated compared with patient referral with contact cards. ${ }^{\text {w12w14 }}$

\section{Combinations}

One trial in Zambia found that a greater proportion of index patients receiving one to one counselling and contact cards with information about the importance of seeking care had at least one partner notified compared with the control group. ${ }^{\text {w10 }}$ Another trial in South Africa showed that more partners were treated per index patient in an experimental group receiving both standardised verbal health education messages

\begin{tabular}{|c|c|c|c|c|c|}
\hline \multicolumn{6}{|c|}{ Partners treated per elicited partner } \\
\hline Study & $\begin{array}{c}\text { No of } \\
\text { patients }\end{array}$ & $\begin{array}{l}\text { Weight } \\
\text { (\%) }\end{array}$ & \multicolumn{2}{|c|}{$\begin{array}{l}\text { Risk ratio } \\
(95 \% \mathrm{Cl})\end{array}$} & $\begin{array}{c}\text { Risk ratio } \\
(95 \% \mathrm{CI})\end{array}$ \\
\hline Kissinger et al $2005^{\mathrm{w} 2}$ & 692 & 71 & & & 1.22 (1.10 to 1.36$)$ \\
\hline Kissinger et al $2006^{\mathrm{w} 1}$ & 308 & 29 & & & $1.32(1.12$ to 1.55$)$ \\
\hline \multirow[t]{3}{*}{ Overall $\left(I^{2}=0 \%, \mathrm{P}=0.44\right)$} & & & & & 1.25 (1.15 to 1.37$)$ \\
\hline & & 0. & 0.5 & 1 & \\
\hline & & \multicolumn{2}{|c|}{$\begin{array}{l}\text { Favours patient } \\
\text { referral } \\
\text { supplemented } \\
\text { by additional } \\
\text { information } \\
\text { for partners }\end{array}$} & $\begin{array}{r}\text { Fav } \\
\text { pa } \\
\text { deliv } \\
\text { pa } \\
\text { the }\end{array}$ & \\
\hline
\end{tabular}

Fig 3 Random effects meta-analysis of secondary outcome in trials comparing patient delivered partner therapy with patient referral supplemented by information for partners. Both trials had unclear or inadequate concealment of allocation and individual counselling compared with patient referral with contact cards. ${ }^{\text {w14 }}$ The other trials found no differences between experimental interventions and patient referral with or without contact cards on various outcomes (table). ${ }^{\text {w11w13 }}$ The outcomes reported were too different to permit meta-analysis.

\section{Adverse effects}

Only two trials, both studying syndromically diagnosed infections, reported adverse effects of partner notification. ${ }^{\text {w5 } 9}$ In the trial from Zimbabwe, ${ }^{\text {w9 }}$ the authors stated that no differences were found between groups (see table of included studies on www.ispm. ch/index.php?id=1193). The trial from Uganda compared patient delivered partner therapy with simple patient referral. $^{\mathrm{w} 5}$ Overall, around $10 \%$ of patients reported quarrelling, with no difference between groups. This analysis was not based on the intention to treat population and substantially more dropouts were from the control group.

\section{DISCUSSION}

This systematic review summarised studies of new strategies that involve patients with sexually transmitted infections in shared responsibility for the care of their sexual partners. Five trials of patient delivered partner therapy reported effects on persistent or recurrent infections in index patients. ${ }^{\text {w1-w4w6 }}$ ${ }^{\text {w13 }}$ Patient delivered partner therapy was superior to patient referral with or without contact cards, but the absolute effects were modest. Patient delivered partner therapy did not, however, reduce persistent or recurrent infections in index patients when compared with simple patient referral supplemented by information for partners. ${ }^{\text {w1w2 }}$ Two trials found that offering home sampling kits to partners resulted in more partners being tested compared with sampling at a doctor's surgery, ${ }^{\text {ww8 } 8}$ but the control intervention was not comparable to that used in other studies. Several trials examined different ways of providing additional information to index patients. Interventions that combine additional written and verbal information might be superior to simple patient referral alone. ${ }^{\text {w10w14 }}$ No trial directly compared simple patient referral with patient referral using contact cards (see figure on www.ispm.ch/index.php? $\mathrm{id}=1193)$. All trials had methodological limitations and reporting quality was poor.

\section{Strengths and weaknesses}

Our review included studies of both women and men with a range of curable sexually transmitted infections in developed and developing countries. We searched multiple databases and reference lists so it is unlikely that we missed relevant controlled trials. We minimised subjectivity by carrying out study selection, data extraction, and quality assessment in duplicate and used validated, replicable criteria for quality assessment. ${ }^{13}$ Our conclusions were, however, limited by the quality of included studies and the information 
provided. Despite the large overall number of participants, differences in the interventions and outcomes limited the use of meta-analysis to summarise results and explore heterogeneity. Also our results apply only to sexually transmitted infections that cause urethritis, cervicitis, and vaginitis because we did not find any relevant trials including patients with syphilis, HIV, or other sexually transmitted infections.

\section{Comparison with previous research}

The new strategies identified in our review involved methods that made it easier for the index patient to share responsibility for the care of their sexual partners. Traditionally partner notification has emphasised the duty of confidentiality to the index patient, even if this deters partners from seeking treatment. ${ }^{17}$ Observational evidence has suggested that providing more information about the sexually transmitted infection is acceptable to both index patients and partners. ${ }^{17}$ We identified seven randomised trials investigating patient delivered partner therapy ${ }^{\mathrm{w} 1-\mathrm{w} 6}$ or home sampling, ${ }^{\text {w8 }}$ and two trials in resource poor settings ${ }^{\mathrm{w} 5} \mathrm{w} 9$ that have not been included in previous reviews. ${ }^{4112}$ A narrative review of US trials of expedited partner therapy, which is the term used in the United States for any method that aims to speed up treatment for sex partners without an intervening medical evaluation or counselling, reached conclusions similar to ours. ${ }^{18}$

\section{Effectiveness of methods to enhance patient referral}

Our review shows that the primary outcome in future trials of partner notification should be a reduction in infection rates because surrogate end points might be misleading. Patient delivered partner therapy was superior to simple patient referral for both biological and behavioural outcomes. However, when patient delivered partner therapy was compared with patient referral in which index patients were also given information for their sexual partners and treatment guidelines for the doctor, an increase in the numbers of partners treated did not translate into a reduction in persistent or recurrent infections. ${ }^{\text {ww2 }}$ It is possible that the benefits of supplemented patient referral follow from more careful ascertainment of sexual contact histories and extra discussion about the infection, rather than the use of contact cards, which are rarely returned. ${ }^{19}$ This is supported by the finding that when simple patient referral included contact cards for index cases, most trials providing further written or verbal information did not show an increase in the numbers of sexual partners treated. ${ }^{\text {w12-w14 }}$ Patient delivered partner therapy was beneficial in patients with chlamydia, gonorrhoea, and syndromic diagnoses, ${ }^{\text {w2-w5 }}$ but not in women with trichomonas. ${ }^{\text {w1 }}$ The reasons for this are not clear.

\section{Implications for research and practice}

The number of doctors who practise patient delivered partner therapy is increasing. ${ }^{72021}$ According to the
Medicines and Healthcare Regulatory Authority similar strategies are legal in the United Kingdom if the partner is assessed by a health professional. This assessment can be done by telephone or by pharmacists supplying the drugs. An intervention to accelerate partner therapy in the United Kingdom is being developed (C Estcourt, personal communication, 2006). Providing patients diagnosed as having chlamydia with self sampling kits for their partners is also being evaluated in a UK based randomised controlled trial (ISRCTN12617257). Patient delivered partner therapy also improved outcomes for syndromically diagnosed infections in Uganda, ${ }^{\mathrm{w} 5}$ a resource poor country where elaborate interventions are not feasible. ${ }^{322}$ The poor specificity of syndromic management algorithms in women, however, exposes them to the risk of gender based violence. ${ }^{3}$ Trials in Africa were the only ones in our review to have reported on the adverse effects of partner notification. Strategies to improve the effectiveness of patient referral for syphilis and HIV should also be evaluated to expand the options available to patients with these infections.

Future randomised trials of partner notification must follow agreed standards of conduct and reporting. ${ }^{23}$ More than 10 years have passed since the consolidated standards of reporting trials statement was first published, ${ }^{24}$ but even the most recent trials in this review did not report essential methodological details such as methods of randomisation and allocation concealment. When the sequence of randomisation was clearly not concealed ${ }^{\mathrm{w} 2}$ imbalances between groups in the numbers of participants suggest that allocation was not truly random and that the benefit of the intervention might have been overestimated. Furthermore, the benefits of patient delivered partner therapy might have been exaggerated by differences in the content of interventions or ascertainment of outcomes. In five trials index patients in the experimental group received additional materials, ${ }^{\text {w1-w4 }}$ including condoms ${ }^{\text {w3 }}$ or reimbursements, ${ }^{\mathrm{w} 5}$ which were not given to the control group.

\section{Conclusion}

Involving index patients in shared responsibility for the management of sexual partners improves outcomes. Health professionals should consider the following strategies for the management of individual patients: patient delivered partner therapy, home sampling for partners, and providing additional information for partners.

Contributors: ST searched the literature, selected articles, extracted and analysed the data, and drafted the manuscript. AS selected articles, extracted the data, and revised the manuscript. LN selected articles and revised the manuscript. JAC obtained funding, retrieved the data, and revised the manuscript. NL obtained funding, supervised the review, revised the manuscript, and is guarantor for the paper. All authors approved the final version.

Funding: ST, AS, LN, and NL are or were employed by the University of Bern which received funding from the UK National Institute for Health and Clinical Excellence. Parts of the research referred to in this article were commissioned by NICE to inform the development of its forthcoming guidance on the prevention of sexually transmitted infections. The full report is available on 


\section{WHAT IS ALREADY KNOWN ON THIS TOPIC}

The stigma attached to sexually transmitted infections makes partner notification difficult Patient referral is preferred by patients and doctors for most curable sexually transmitted infections

\section{WHAT THIS STUDY ADDS}

Involving index patients in the care of sexual partners improves the outcomes of partner notification for chlamydia, gonorrhoea, and non-specific urethritis

Patient delivered partner therapy, home sampling, and additional information for partners are more effective than simple patient referral

Simple patient referral combined with additional information for partners might be as effective as patient delivered partner therapy

www.nice.org.uk/page.aspx?0=371771. The opinions expressed in the article are those of the authors and not the institute. This article does not constitute NICE guidance. The funding source had no role in the conduct or analysis of the study and no influence on the decision to publish the results. All authors had full access to all data of the study.

Competing interests: None declared.

Ethical approval: Not required.

1 Society for Sexual Health Advisers. The manual for sexual health advisers. London: SSHA, 2004.

2 World Health Organization and Joint United Nations Programme on HIV/AIDS. Sexually transmitted diseases: policies and principles for prevention and care. Geneva: UNAIDS Best Practice Collection, 1999.

3 Low N, Broutet N, Adu-Sarkodie Y, Barton P, Hossain M, Hawkes S. Global control of sexually transmitted infections. Lancet 2006;368:2001-16.

4 Mathews C, Coetzee N, Zwarenstein M, Lombard C, Guttmacher S, Oxman A, et al. Strategies for partner notification for sexually transmitted diseases. Cochrane Database Syst Rev 2001;4:CD002843.

5 Apoola A, Radcliffe KW, Das S, Robshaw V, Gilleran G, Kumari BS, et al. Patient preferences for partner notification. Sex Transm Infect 2006;82:327-9.

6 Hogben M, St Lawrence JS, Montano DE, Kasprzyk D, Leichliter JS, Phillips WR. Physicians' opinions about partner notification methods: case reporting, patient referral, and provider referral. Sex Transm Infect 2004;80:30-4.

7 St Lawrence JS, Montano DE, Kasprzyk D, Phillips WR, Armstrong K, Leichliter JS. STD screening, testing, case reporting, and clinical and partner notification practices: a national survey of US physicians. Am J Public Health 2002;92:1784-8.

8 Arthur G, Lowndes CM, Blackham J, Fenton KA. Divergent approaches to partner notification for sexually transmitted infections across the European Union. Sex Transm Dis 2005;32:734-41.
9 Cassell JA, Mercer CH, Sutcliffe L, Petersen I, Islam A, Brook MG, et al. Trends in sexually transmitted infections in general practice 1990-2000: population based study using data from the UK general practice research database. $B M J$ 2006;332:332-4.

10 Low N, Welch J, Radcliffe K. Developing national outcome standards for the management of gonorrhoea and genital chlamydia in genitourinary medicine clinics. Sex Transm Infect 2004;80:223-9.

11 Oxman AD, Scott EA, Sellors JW, Clarke JH, Millson ME, Rasooly I, et al. Partner notification for sexually transmitted diseases: an overview of the evidence. Can J Public Health 1994;85(Suppl 1): S41-7.

12 Macke BA, Maher JE. Partner notification in the United States: an evidence-based review. Am / Prev Med 1999;17:230-42.

13 National Institute for Clinical Excellence. Guideline development methods: information for national collaborating centres and guideline developers. London: NICE, 2005.

14 DerSimonian R, Laird N. Meta-analysis in clinical trials. Control Clin Trials 1986;7:177-88

15 Higgins JP, Thompson SG, Deeks JJ, Altman DG. Measuring inconsistency in meta-analyses. BMJ 2003;327:557-60.

16 Egger M, Davey SG, Schneider M, Minder C. Bias in meta-analysis detected by a simple, graphical test. BMJ 1997;315:629-34.

17 Wright A, Chippindale S, Mercey D. Investigation into the acceptability and effectiveness of a new contact slip in the management of Chlamydia trachomatis at a London genitourinary medicine clinic. Sex Transm Infect 2002;78:422-4.

18 Centers for Disease Control and Prevention. Expedited partner therapy in the management of sexually transmitted diseases. Atlanta, GA: US Department of Health and Human Services, 2006.

19 Low N, McCarthy A, Roberts TE, Huengsberg M, Sanford E, Sterne JA, et al. Partner notification of chlamydia infection in primary care: randomised controlled trial and analysis of resource use. $B M J$ 2006;332:14-9.

20 Hogben M, McCree DH, Golden MR. Patient-delivered partner therapy for sexually transmitted diseases as practiced by US physicians. Sex Transm Dis 2005;32:101-5.

21 Andersen B, Ostergaard L, Nygard B, Olesen F. Urogenital Chlamydia trachomatis infections in general practice: diagnosis, treatment, follow-up and contact tracing. Fam Pract 1998;15:223-8

22 Hawkes S, Mabey D, Mayaud P. Partner notification for the control of sexually transmitted infections. BMJ 2003;327:633-4.

23 Moher D, Schulz KF, Altman DG. The CONSORT statement: revised recommendations for improving the quality of reports of parallel-group randomized trials. Ann Intern Med 2001;134:657-62.

24 Begg C, Cho M, Eastwood S, Horton R, Moher D, Olkin I, et al. Improving the quality of reporting of randomized controlled trials. The CONSORT statement. JAMA 1996;276:637-9.

Accepted: 6 December 2006 